\title{
A PRIORIDADE TEMPORAL DA OUSÍA E A NOÇÃO DE SEPARAÇÃO NO LIVRO Z DA METAFÍSICA DE ARISTÓTELES
}

\author{
THE TEMPORARY PRIORITY OF OUSÍA AND THE NOTION OF SEPARATION IN THE BOOK Z \\ ARISTOLE'S METAPHYSICS
}

\author{
Francisco Messias Cândido de Medeiros ${ }^{1}$
}

\section{RESUMO}

Esta comunicação visa abrir a discussão sobre a separação da substância apresentada por Aristóteles no Livro Z da Metafísica. Em Z 1 a substância é anterior em três aspectos, a saber quanto à definição, ao conhecimento e ao tempo. A justificativa de Aristóteles de que a substância é primeira no tempo é porque ela é a única das categorias que é separada. Com base em intérpretes contemporâneos, discutiremos a separação como separação ontológica associada ao correlato de separação definicional, apresentando, assim, um escopo embrionário da pesquisa de mestrado que está em andamento.

PALAVRAS-CHAVE: Aristóteles. Metafísica. Substância. Separação.

\section{ABSTRACT}

This communication aims to open the discussion about the separation of the substance presented by Aristotle in Book Z of Metaphysics. In Z 1 the substance is prior in three aspects, namely as to the definition, the knowledge and the time. Aristotle's justification that substance is first in time is because it is the only category that is separate. Based on contemporary interpreters, we will discuss the separation as ontological separation associated with the definitional separation correlate thus presenting an embryonic scope of the master's research that is underway.

KEY-WORDS: Aristotle. Metaphysics. Substance. Separation.

No início do Livro Z da Metafísica Aristóteles pontua três prioridades fundamentais da substância: “[...] o que é primeiramente, o que não é em algum aspecto, mas simplesmente, será a substância. Mas primeiro se diz em muitos sentidos. Pois bem, em todos eles é primeira a substância: enquanto à definição, ao conhecimento e ao tempo. (Met. 1028a 30-34, grifo nosso). Nas linhas que se seguem, Aristóteles justifica por que a substância é anterior no tempo: "De fato, nenhuma das outras categorias é capaz de existência separada, mas somente ela.” (ton mèn gàr állon katerogmáton outèn choristón - Met. 1028a 33-34). O que significa “existência separada"? Qual a compreensão que Aristóteles tem da substância como sendo separada no tempo?

\footnotetext{
${ }^{1}$ Mestrando do curso de Filosofia da Universidade Federal de Minas Gerais (UFMG). Licenciado em Filosofia pela Universidade do Estado do Rio Grande do Norte (UERN). Bacharel em Teologia pela Faculdade Jesuíta de Filosofia e Teologia (FAJE) de Belo Horizonte e bolsista pela FAPEMIG. Nossa gratidão à FAPEMIG por
} 
A interpretação clássica das 11. 33-34 é a que justifica a prioridade no tempo da substância a partir da independência existencial, isto é, a substância existe de modo autônomo, independentemente dos acidentes que lhe possam ser atribuídos. Esse modo de compreender a substância perpassou a história e chegou até os dias hodiernos com a interpretação "tradicional" da existência autônoma do primeiro sentido do ser. Desse modo, é possível entender o que Alexandre de Afrodísia (2007, p. 1205) quis afirmar ao comentar essa passagem. Ele reconhece que:

\begin{abstract}
Embora a substância não possa nunca existir separadamente das outras categorias (já que não existe nunca uma, entre as substâncias sujeitas à geração, que seja privada de qualidade ou quantidade ou de similares características), embora portanto não exista nunca separadamente das outras categorias, todavia, porque são dela separadas (algumas estão nela hoje, outras ontem e outras ainda amanhã, e isso se verifica, podendo-se dizer, para cada uma delas), é evidente que essa é, pelo tempo, anterior às outras. De fato, como por exemplo a ânfora é anterior pelo tempo ao vinho que de vez em quando vem a encontrar-se nela, assim a substância é anterior aos acidentes que todo dia estão nela presentes ou ausentes. (Tradução nossa).
\end{abstract}

Esse tipo de interpretação dá margem a pensar, de fato, na existência independente da substância. Ora, se o vinho, como no exemplo dado, vem a estar de vez em quando na ânfora, podendo ter estado ontem e estar hoje e amanhã e podendo também não estar, a ânfora sempre será anterior ao vinho pois existirá independentemente de o vinho estar nela ou não. Tome-se como exemplo "homem" e "branco". Parece não ser possível dizer simplesmente "homem" sem lhe atribuir alguma característica. De fato, soaria estranho e não haveria sentido não dizer algo de "homem" assim como não há sentido em dizer simplesmente "branco" fora de uma substância. O "branco" como qualidade cromática de "homem" pode estar nele hoje e pode não estar amanhã, caso a substância "homem" mude de cor. Nesse sentido, parece que as categorias são recebidas da substância. Com efeito, “o exegeta explica que essa (a substância) depende seja do fato que as categorias são recebidas da substância em uma sucessão temporal, seja do fato que essa não falta se lhe faltam alguns dos seus atributos, mas não vice versa." (MOVIA, 2007, p. 89). Se faltar os atributos não falta a substância, mas é falso o contrário. No entanto, de que maneira é possível pensar que uma substância tenha existência independente se nenhum atributo lhe for conferido?

Nesse sentido, é possível dizer que determinada substância $x$ pode existir independentemente dos atributos que se lhe possam ser dados e isso significa, do mesmo modo, pensar na possibilidade de haver alguma substância que exista sem nenhum atributo. Pois se ela tem existência independente tanto faz que tenha tal qualidade ou tal quantidade, ou 
mesmo qualquer outro atributo ou até mesmo nenhum. Mas é verdadeiramente possível que uma substância tenha existência independente? Isso é o que se pretende discutir.

Da mesma forma, ao comentar essa passagem das 11. 33-34, Santo Tomás de Aquino dá margem a pensar na independência existencial da substância. Com efeito, ele diz:

\begin{abstract}
Ele prova que é primeira no tempo por este argumento: nenhuma das outras categorias é capaz de existir separada da substância, mas a substância sozinha é capaz de existir separada das outras; pois nenhum acidente é encontrado sem a substância, mas alguma substância é encontrada sem um acidente. Assim está claro que um acidente não existe sempre que uma substância, mas o contrário é verdadeiro. E por essa razão a substância é primeira no tempo. (AQUINO, Exp. Metaph., Lib VII, lect. 1, n. 1257; 1961, tradução nossa).
\end{abstract}

Parece estar claro que Santo Tomás também entende que a substância ser primeiro no tempo por ser separada significa uma existência autônoma já que é possível encontrar alguma que não tenha atributos. Uma substância, com efeito, pode existir sem que lhe sejam dados determinados atributos. A que substância Santo Tomás se refere? Seria às substâncias sensíveis ou àquela substância eterna e imóvel, o Primeiro Movente? É possível que haja alguma substância sensível em sentido primeiro ("um certo homem", "um certo cavalo etc.) que não tenha atributos e, consequentemente, tenha independência existencial?

Um intérprete mais contemporâneo, mas não menos importante, também parece seguir a mesma interpretação tradicional. Enrico Berti, ao comentar o que significa "ser separada" ( $\chi \omega \rho ı \sigma \tau o ́ v)$, condição dada por Aristóteles para que algo possa ser considerado substância juntamente com "ser um este” ( $\tau$ ó $\delta \varepsilon \tau$ ), diz que: “'Separada' quer dizer que existe em si, e não em outro, que para existir não tem necessidade de ser em outro, mas existe em si, separadamente do resto; [...].” (BERTI, 2012, p. 99). Existir em si pode ser entendido como capaz de existir só, é subsistente e, em outros termos, tem independência existencial. Com efeito, é possível afirmar que um certo homem é separado, pois pode existir independentemente de outra coisa ou das demais formas de se dizer o ser. Se, portanto,

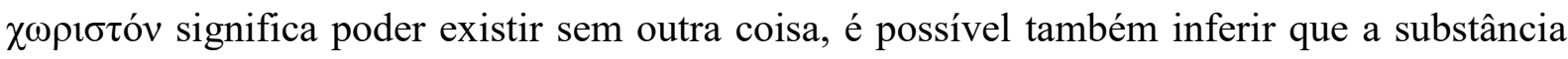
que detém essa característica é primeira no tempo por poder existir sem outra coisa, isto é, tem existência independente.

Aristóteles nessa passagem de Met. Z 1 fala nas prioridades da substância (definição, conhecimento e tempo). O tema da prioridade em Aristóteles é bastante amplo, mas interessante à pesquisa por estar associado, direta ou indiretamente, ao tema da substância. Uma prioridade em particular que merece destaque aparece em Met. $\Delta 11 \mathrm{em}$ que o Estagirita 
diz: "Algumas coisas se dizem que são anteriores e posteriores nesse sentido, e outras que são segundo a natureza e a substância (kata phýsin kaì ousían): assim, todas as coisas que podem existir sem outras, mas não estas sem elas, [...].” (Met. 1019a 2-3). Esse tipo de prioridade pode ser definido como a prioridade em existência. Neste caso, é possível dizer, por exemplo, que $A$ é anterior a $B$ se duas condições forem satisfeitas:

I5: $A$ pode existir independentemente de $B$, ou seja, pode existir sem que $B$ exista ao mesmo tempo;

II5: $B$ não pode existir independentemente de $A$, ao contrário, se $B$ existe, $A$ necessariamente existe ao mesmo tempo.

A prioridade em independência quanto a essas condições de existência são equacionadas à prioridade temporal da substância que lhe confere o título de "separada"? De acordo com Angioni (2010) a resposta é negativa. Para ele a prioridade em existência de Met. $\Delta 11$ não é suficiente para determinar a primazia ontológica da substância, pois "seria impossível encontrar algo que, não sendo substância, mesmo assim satisfizesse os requisitos para ser considerado como 'anterior em existência'” (ANGIONI, 2010, p. 88). Ao contrário, é possível encontrar algo que, não sendo substância, tenha prioridade em independência quanto às condições em existência:

\footnotetext{
De fato, o calor é anterior em existência ao animal, pois (i5) o calor pode existir independentemente da existência de animais; (ii5) mas nenhum animal pode existir independentemente da existência do calor, ao contrário, se há animais, necessariamente existe calor ao mesmo tempo. No entanto, o calor não é uma substância, sendo, porém, anterior a um amplo gênero de substâncias (os animais) quanto às condições de existência. (ANGIONI, 2010, p. 88).
}

O ponto de Angioni é esclarecer que a prioridade em existência não é necessária nem suficiente para determinar a primazia ontológica da substância. Sua proposta é, por assim dizer, equacionar a prioridade em existência com a prioridade em substância (Met. M 1077b 2). Essa prioridade em substância seria caracterizada pelos seguintes critérios:

I7: $A$ constitui um todo perfeito e acabado, no qual $B$ pode estar de certo modo incluído;

II7: $B$ não constitui um todo acabado, no qual se pudesse dizer que $A$ está incluído.

Angioni esclarece seu argumento se utilizando do seguinte exemplo: 
[...] pode-se dizer que o adulto é "anterior em substância à criança" (1050a 5-6 ${ }^{2}$ ), porque (I7) o adulto constitui um todo perfeito e acabado, algo a que nada falta em referência ao qual a criança pode ser entendida como uma etapa em sua gênese e desenvolvimento; (II7) mas a criança não constitui um todo acabado, em referência ao qual o adulto pudesse ser entendido como uma etapa em sua gênese e desenvolvimento. (ANGIONI, 2010, p. 93).

Fica claro, portanto, que a interpretação que remonta a Alexandre de Afrodísia a qual compreende o título de "algo separado" dado à substância como independência em termos de condição de existência não é razoavelmente sustentável. A terminologia da separação está, então, intimamente relacionada com a noção de prioridade. $\mathrm{E}$ isso faz pensar, outrossim, nas noções de dependência e independência. Contudo, a noção importante de prioridade em natureza e em substância (prioridade em existência) precisa ser distinguida de vários outros sentidos também relevantes de prioridade, como por exemplo, prioridade lógica ou definicional $^{3}$, prioridade na atualidade e potencialidade, prioridade causal, prioridade ontológica dentre outras, algo impossível de se fazer numa comunicação desta natureza.

Em várias passagens do corpus há inúmeras ocorrências do termo choris e seus derivados (choriston, choristós, choridzein etc.). Em outros contextos, não aparece a terminologia da separação, mas da subtração ou abstração, sendo esses termos traduções para a expressão "tá ex aphaireseos". Em alguns momentos, Aristóteles diz "separado" e em outros diz "por abstração" para expressar a mesma ideia. Na Física 193b 31-35 Aristóteles utiliza a terminologia da "separação": “[...] o matemático os separa: pelo pensamento, tais itens são separáveis do movimento [...]"5. Sobre o mesmo assunto (o objeto de estudo da matemática), na Metafísica K 1061a 29-30 ele utiliza a terminologia da abstração: “[...] o matemático estuda noções obtidas por abstração [...]"6. A expressão grega tá ex aphaireseos assume nessa passagem o mesmo sentido que Aristóteles atribui a $\chi \omega \rho i ́ \varsigma$ em outras passagens.

Morrison (1985) fez um estudo minucioso das várias ocorrências do termo choristón no corpus aristotelicum. E nas passagens que ele considera "problemáticas", há uma em particular que diz respeito à substância. É a passagem de Geração e Corrupção 327b 19 em que Aristóteles diz: “[...] não é possível haver mistura do branco e do saber, nem de nenhuma

\footnotetext{
2 "Mas o ato também é anterior pela substância. Em primeiro lugar, porque as coisas que na ordem da geração são últimas, na ordem da forma e da substância são primeiras: por exemplo, o adulto é antes da criança e o homem é antes do esperma: de fato, um já possui a forma em ato, enquanto o outro não." (ARISTÓTELES, Met. 1050a 1-6).

${ }^{3}$ Em Z 1 Aristóteles aponta para esse tipo de prioridade assim como a prioridade no conhecimento.

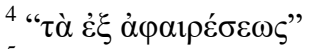

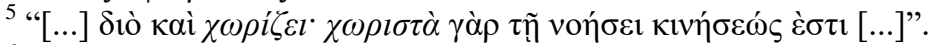

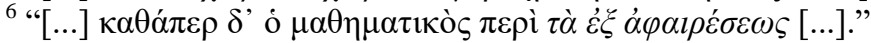

${ }^{7}$ DA 413b 28; 427a 2; GC 316b 3; 329a 25; Fís. 186b 28; 193b 34; 209b 27; Sens. 449a 15; Somnvig. 455 a 24.
} 
outra coisa que não possua existência separada". Conforme Morrison, nessa passagem está implícito o conceito aristotélico de que os acidentes não são separados da substância. Em outros termos, os acidentes não podem ser ontologicamente independentes já que podem ser ditos apenas com relação à substância: "Acredito que Aristóteles segurou aquela informação, mas também acredito que ele possuía outra doutrina igualmente importante para ele, a saber, que os atributos não são separados da substância." (MORRISON, 1985, p. 97, tradução nossa).

De posse desses preâmbulos sobre o status questionis do problema, da noção de prioridade e de alguns poucos aspectos da separação, é possível levantar uma hipótese que, de modo algum, pretenda ser estanque ou resolver toda a questão. Mas uma hipótese que permita compreender ou mesmo discutir o problema que, de uma forma ou de outra, permanece aberto na discussão entre os intérpretes. Apresentarei a hipótese que equaciona separação ontológica, mas que não implica necessariamente existência independente e separação de tipo definicional.

Entre os comentadores é clara a noção de que o Estagirita aponta a substância com uma separação que lhe é própria, uma separação de tipo ontológica caracterizada pelo termo "separado". De acordo com Angioni (2008) o objetivo e interesse de Aristóteles em Z da Metafísica é, sobretudo, refutar a tese platônica da separação das Formas e entidades matemáticas. Os platônicos postularam que tais "substâncias" seriam separadas das coisas sensíveis e que pelo teste da codestruição ${ }^{8}$ (synanairesis) seria possível discernir relações de prioridade explanatória e ontológica. Para discernir o que é anterior do ponto de vista ontológico, tal teste levaria às primeiras substâncias, ou seja, às entidades que subsistem em si mesmas (Formas e entidades matemáticas), separadas das coisas sensíveis. Isso, no fundo, entre outros pontos, parece que é o ponto fulcral que Aristóteles não pode aceitar. Ele, com efeito, atribui aos platônicos a ideia de que é possível que existam universais não instanciados, e a posição do Estagirita é que isso é impossível. Para Aristóteles, é notório que a qualidade de ser branco, por exemplo, só existe em um subjacente (hypokéimenon). O branco jamais pode existir em si mesmo, à parte de um subjacente (ou sujeito) como homem, por exemplo. Semelhantemente acontece com as entidades matemáticas, pois o ponto jamais pode existir em si mesmo, à parte de um corpo sensível. Na verdade, os números como entidades matemáticas não podem ser substâncias, como queriam os platônicos, pois número é quantidade. Então, o branco só existe num composto de matéria e forma (subjacente). Desse

\footnotetext{
8 “ $x$ é anterior a $y$ ” somente se $x$ sobrevive à destruição de $y$, ao passo que $y$ é codestruído pela destruição de $x$.
} 
modo, a prioridade ontológica que é própria da substância não poderia ser equacionada à prioridade em termos de condições de existência, como já visto, mas tal prioridade ontológica nunca poderia ser negada à substância, pois qualquer outro atributo só é dito em relação A uma substância. Ora, se Aristóteles sustenta a prioridade ontológica das substâncias sensíveis, isso se dá pelo fato de que não-substâncias (números matemáticos, calor etc.) e substâncias universais (homem ${ }^{9}$ ) são ontologicamente dependentes de substâncias individuais e que estas são ontologicamente independentes tanto das não-substâncias quanto de substâncias universais (CORKUM, 2008).

Junto à prioridade ontológica pode-se acrescentar uma prioridade de tipo definicional defendida por Spellman (1995). Duas condições precisam ser satisfeitas para que algo possa ser dito anterior em definição, a saber $\mathrm{C} 1$ : $A$ pode ser definido independentemente de $\mathrm{B}$, por um enunciado definitório em que o termo $B$ não é mencionado nem está implicitamente contido; $\mathrm{C} 2: B$ não pode ser definido independentemente de $A$, ao contrário, o enunciado definitório de $B$ inclui $A$ como um de seus termos. Poderíamos, portanto, dizer que homem é (df:) animal dotado de atividade racional da alma. A substância "homem" foi definida por um enunciado em que a qualidade de "ser branco" não foi mencionada, caso o homem fosse branco. O contrário não se aplica, pois não seria possível definir a qualidade de ser branco independentemente da substância, mesmo que nos arriscássemos em definir branco como "qualidade cromática", poderíamos perguntar: qualidade cromática de quê? Isso é, com efeito, o que Aristóteles parece afirmar em Met. 1028a 35-36 quando diz que na noção das demais categorias está a noção de substância e em Met. 1045b 29-31 quando diz que todas as demais categorias devem ter uma relação com a substância. Nesse sentido, para definir uma substância não é necessário referir-se às suas qualidades, mas o inverso não se aplica. E isso não significa dizer necessariamente que a substância tenha uma independência existencial, mas tão somente que ela tem uma primazia que lhe é própria. Caso tivesse existência autônoma poderia ser desprovida de qualidade, quantidade e dos demais atributos e, grosso modo, Aristóteles não parece conceber nenhuma substância dessa maneira. Spellman (1995, p. 86) aposta nesse correlato ontológico à separação em definição em que " $A$ seria tal que $B$ não é em nenhum momento (parte de) aquilo que A é em si.".

\footnotetext{
${ }^{9}$ Homem, para Aristóteles, não é substância; não existe o homem universal; existe a espécie humana, mas ela ainda não é substância, pois a verdadeira substância são os indivíduos aos quais pertence esta característica de ser homem.
} 
Essas duas hipóteses que se imbricam devem ser postas em confronto com a noção de substância que Aristóteles desenvolve no decorrer do livro Z. Pois, se a substância é entendida por Aristóteles como sendo a Forma, torna-se mais complexo atribuir os diversos tipos de separação. Mas se a substância é o composto (matéria e forma) não seria difícil supor que todos os sentidos de separação relevantes pudessem ser aplicados. O ponto a partir disso consiste em discutir o desenvolvimento que Aristóteles dá à questão e propor a reflexão do problema. Arrisco-me a dizer, embrionariamente, que Aristóteles, embora tenha como objetivo implícito refutar as teorias platônicas, também faça um enorme esforço em equilibrar sua posição de não somente assumir a forma como sendo o fundamental e substância, mas também em negar que a Forma platônica seja separada das coisas sensíveis. Nem a Forma isolada, existente em si, pois cairia no platonismo, tampouco no composto pura e simplesmente, já que a matéria enquanto substrato não é, para Aristóteles, todé ti, isto é, algo determinado, pois necessita da forma. Por outro lado, a forma pode até satisfazer a condição de ser algo determinado, mas junto com a matéria e, sem esta, a forma não seria separada nem algo determinado. Por isso que o composto permite a Aristóteles negar a pré-existência das Formas e negar, do mesmo modo, que elas sejam separadas das coisas sensíveis.

\section{REFERÊNCIAS}

ARISTÓTELES. Metafísica. Trad. Tomás Calvo Matínez. Editorial Gredos: Madrid, 1994.

AQUINAS, Thomas. Commentary on the Metaphisycs. Translated by John P. Rowan. Chicago, 1961. Disponível em: https://dhspriory.org/thomas/english/Metaphysics.htm.

ANGIONI, Lucas. As noções aristotélicas de substância e essência. Campinas: Editora da Unicamp, 2008.

ANGIONI, Lucas. Prioridade e substância na Metafísica de Aristóteles. Dois pontos, Curitiba. vol.7, n.3, p. 75-106, abr. 2010.

ALESSANDRO DI AFRODÍSIA. Commentario alla Metafisica di Aristotele. A cura di Giarcalo Movia. Milano: Bompiani, 2007.

BERTI, Enrico. Estrutura e significado da Metafísica de Aristóteles. São Paulo: Paulinas, 2012.

CORKUM, Phil. Aristotle on Ontological Dependence. Phronesis. Leiben. vol. 53, p. 65-92, 2008 . 


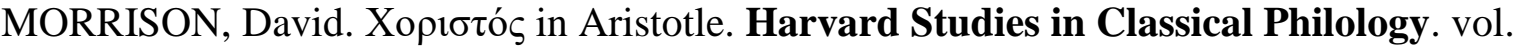
89, p. 89-105, 1985.

MOVIA, Giarcalo. Introduzione. In: ALESSANDRO DI AFRODÍSIA. Commentario alla Metafisica di Aristotele. A cura di Giarcalo Movia. Milano: Bompiani, 2007. p. 11-131.

SPELLMAN, Lynne. Substance and separation in Aristotle. New York: Cambridge University Press, 1995. 